Supporting Information for

Structural Effects of the Donor Moiety on Reduction Kinetics of Oxidized Dye in

\title{
Dye-Sensitized Solar Cells
}

Jun-ichi Ogawa ${ }^{\dagger}$, Saurabh Agrawal ${ }^{\dagger}$, Nagatoshi Koumura ${ }^{\dagger}$, and Shogo Mori ${ }^{\dagger} \S^{*}$

†Division of Chemistry and Materials, Faculty of Textile Science and Technology, Shinshu

University, Ueda, Nagano 386-8567, Japan

National Institute of Advanced Industrial Science and Technology, Tsukuba, Ibaraki 305-8565, Japan

${ }^{\S}$ Center for Energy and Environmental Science, Shinshu University, Ueda, Nagano 386-8567, Japan

* Corresponding Author:

Shogo Mori, E-mail: shogmori@shinshu-u.ac.jp, TEL: +81-0268-21-5818, FAX:

$+81-0268-21-5496$ 


\section{The complete author list for ref 5 .}

Wenger, S.; Bouit, P.-A.; Chen, Q.; Teuscher, J.; Di Censo, D.; Humphry-Baker, R.;

Moser, J.-E.; Delgado, J. L.; Martín, N.; Zakeeruddin, S. M.; Grätzel, M.

\section{The complete author list for ref 19.}

Frisch, M. J.; Trucks, G. W.; Schlegel, H. B.; Scuseria, G. E.; Robb, M. A.; Cheeseman,

J. R.; Scalmani, G.; Barone, V.; Mennucci, B.; Petersson, G. A.; Nakatsuji, H.; Caricato,

M.; Li, X.; Hratchian, H. P.; Izmaylov, A. F.; Bloino, J.; Zheng, G.; Sonnenberg, J. L.;

Hada, M.; Ehara, M.; Toyota, K.; Fukuda, R.; Hasegawa, J.; Ishida, M.; Nakajima, T.;

Honda, Y.; Kitao, O.; Nakai, H.; Vreven, T.; Montgomery, J. A., Jr.; Peralta, J. E.;

Ogliaro, F.; Bearpark, M.; Heyd, J. J.; Brothers, E.; Kudin, K. N.; Staroverov, V. N.;

Kobayashi, R.; Normand, J.; Raghavachari, K.; Rendell, A.; Burant, J. C.; Iyengar, S.

S.; Tomasi, J.; Cossi, M.; Rega, N.; Millam, J. M.; Klene, M.; Knox, J. E.; Cross, J. B.;

Bakken, V.; Adamo, C.; Jaramillo, J.; Gomperts, R.; Stratmann, R. E.; Yazyev, O.;

Austin, A. J.; Cammi, R.; Pomelli, C.; Ochterski, J. W.; Martin, R. L.; Morokuma, K.;

Zakrzewski, V. G.; Voth, G. A.; Salvador, P.; Dannenberg, J. J.; Dapprich, S.; Daniels, A. 
D.; Farkas, Ö.; Foresman, J. B.; Ortiz, J. V.; Cioslowski, J.; Fox, D. J. Gaussian 09,

Revision B.01, Gaussian, Inc., Wallingford CT, 2010. 